\title{
Study of the Clusterization of CdO Phase in ZnCdO Alloys by Modeling Fullerene-Like $\mathrm{Zn}_{44} \mathrm{Cd}_{4} \mathrm{O}_{48}$ Cluster
}

\author{
L. Ovsiannikova*, V. Kartuzov, I. Shtepliuk and G. Lashkarev \\ Frantsevich Institute for Problems of Material Science, NASU, 3, Krzhyzhanovsky Str., Kiev-142 03680, Ukraine

\begin{abstract}
The structural, cohesive and electronic properties of fullerene-like isolated $\mathrm{Zn}_{44} \mathrm{Cd}_{4} \mathrm{O}_{48}$ cluster with consideration of $\mathrm{CdO}$ phase clusterization are studied in the frames of density functional theory B3LYP/3-21G(d). It is revealed that an enlargement of $\mathrm{CdO}$ phase content in $\mathrm{Zn}_{44} \mathrm{Cd}_{4} \mathrm{O}_{48}$ cluster leads to nonlinear rapid increase in cohesive energy and cluster stability, as well as band-gap energy shrinkage.
\end{abstract}

DOI: 10.12693/APhysPolA.129.A-41

PACS: 73.22.-f, 78.55.Et, 81.05.Dz, 81.07.Bc

\section{Introduction}

Low-dimensional materials have aroused great scientific interest due to their promising applications in photocatalysis and nanoscale optoelectronic devices. In particular, $\mathrm{ZnCdO}$ ternary alloys have been attracting growing attention due to their tunable band-gap.

Despite of the significant progress in the growth technologies for $\mathrm{ZnO}$-based thin films and nanostructures, the problems of the controllable change of a band structure and an introduction of defects in these materials are still unsolved [1-3]. In particular, the main bottleneck is associated with the characterization of the prepared samples, especially in the case of nanoclusters formation inside the material. Experimental studies supplemented by theoretical modeling allow to find out a correlation between optical, electronic and magnetic properties on one side and nanoscale structure of the semiconductor materials on the other side. Such complementary approach gives a possibility to reduce the cost of fabrication of materials with new performance characteristics.

Earlier, it was reported the possibility of implementing the first-principles quantum chemical methods in calculation of the band-gap energy of the isolated Cd-containing $\mathrm{ZnO}$ atomic clusters [4-6]. It was demonstrated that the size increase of fullerene-like $\mathrm{Zn}_{n} \mathrm{O}_{n}$ cluster (where $n=12,36,48,60)$ causes the improvement of its stability (increase in the cohesive energy) and band-gap energy shrinkage. The further study of Zn-by-Cd substitution effect on the electronic properties of $\mathrm{Zn}_{n-x} \mathrm{Cd}_{x} \mathrm{O}_{n}$ clusters in the frames of DFT with B3LYP approach and basis functions $3-21 \mathrm{G}(\mathrm{d})$ revealed that the increase in Cd content leads to lowering the cluster stability and monotonic decrease of the band-gap energy.

In this work, the model of the fullerene-like $\mathrm{Zn}_{44} \mathrm{Cd}_{4} \mathrm{O}_{48}$ cluster with $s p^{2}$ bonds $(8.33$ at.\% $\mathrm{Cd}$ ) is proposed for investigation of the effect of the clusteriza-

*corresponding author; e-mail: avilon57@ukr.net tion of $\mathrm{CdO}$ phase in $\mathrm{ZnCdO}$ on the stability, electronic structure and band-gap energy of $\mathrm{ZnCdO}$ ternary alloys.

\section{Model construction and theoretical framework}

A basis structure for investigation of CdO phase clusterization was chosen in manner similar to that in our previous work [6], where isolated fullerene-like $\mathrm{Zn}_{36} \mathrm{O}_{36}$ cluster with $\mathrm{Zn}$ atoms substituted by $\mathrm{Cd}$ ones was used for study $\mathrm{Cd}$ doping effect on electronic structure and band-gap energy of $\mathrm{ZnCdO}$ ternary alloys. It should be mentioned that the results of calculation for $\mathrm{Zn}_{n-x} \mathrm{Cd}_{x} \mathrm{O}_{n}$ clusters $(n=2,4,6,8,12)$ with $\mathrm{Cd}$ content of $5.5,11,16.7,22$ and 33 at.\%, respectively, showed that the calculated band-gap energy $\left(2.827 \mathrm{eV}\right.$ ) for $\mathrm{Zn}_{34} \mathrm{Cd}_{2} \mathrm{O}_{36}$ cluster (with $\approx 6$ at.\% $\mathrm{Cd}$ ) is in agreement with experimental value of $E_{\mathrm{g}}(2.87 \mathrm{eV})$ for $\mathrm{Zn}_{0.94} \mathrm{Cd}_{0.06} \mathrm{O}$ films grown by dc magnetron sputtering [7]. Therefore, we investigated the $\mathrm{CdO}$ phase clusterization in $\mathrm{ZnCdO}$ alloys within the $\mathrm{Cd}$ content range not exceeding 6 at.\% using the cluster model with the size larger than that of the conventional $\mathrm{Zn}_{36} \mathrm{O}_{36}$ cluster.

Earlier, within the framework of density functional theory (hybrid B3LYP functional) with basis set 6-31G(d) it was shown that both $\mathrm{Zn}_{36} \mathrm{O}_{36}$ and $\mathrm{Zn}_{48} \mathrm{O}_{48}$ clusters could be used as models for investigation of the $\mathrm{Cd}$ doping effect on the electronic properties of $\mathrm{Zn}_{n-x} \mathrm{Cd}_{x} \mathrm{O}_{n}$ clusters. Results of computation presented in Ref. [6] confirm the preliminary prediction of the stability improvement (increase in cohesive energy) and band gap energy shrinkage with increase in the cluster size (see Fig. 1) [4], although no clear trend to reduce of the band-gap with increase in cluster size is observed. The value of the band-gap energy for all clusters does not only depend on the size of the cluster. It can be affected by other factors such as cluster's geometry [8].

Fullerene-like isolated $\mathrm{Zn}_{44} \mathrm{Cd}_{4} \mathrm{O}_{48}$ cluster with four $\mathrm{Cd}$ atoms $(8.33$ at.\% $\mathrm{Cd}$ ) was chosen for modeling the $\mathrm{CdO}$ phase clusterization in $\mathrm{ZnCdO}$.

Three cases of distribution of $\mathrm{Cd}-\mathrm{O}$ atomic pairs in cluster were studied (Fig. 2). In the first case, the cluster 

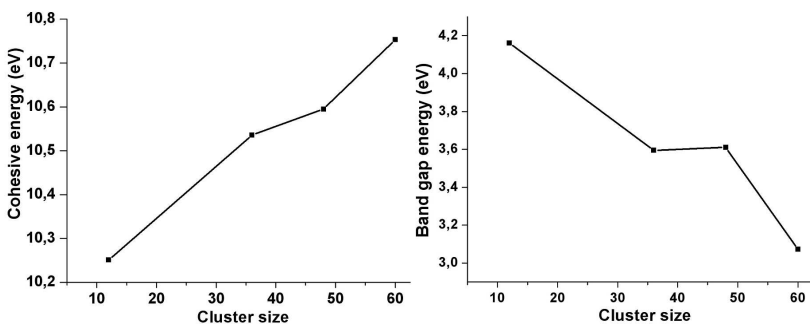

Fig. 1. The dependence of cohesive energy and band gap energy of the $(\mathrm{ZnO})_{n}$ clusters $(n=12,36,48,60)$ on cluster size.

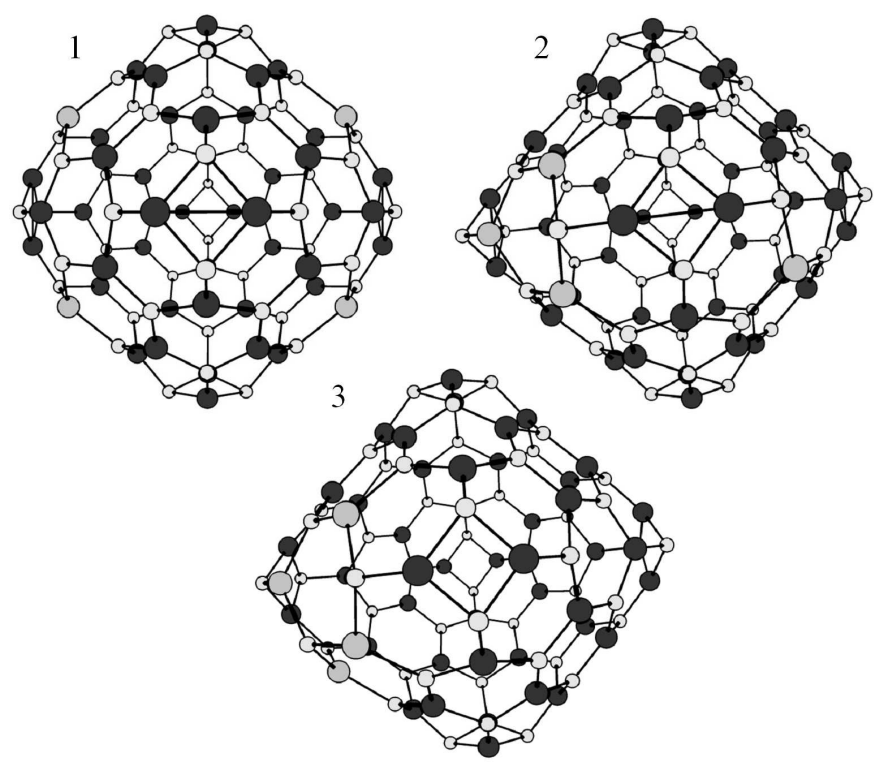

Fig. 2. Optimized geometry of the $\mathrm{Zn}_{44} \mathrm{Cd}_{4} \mathrm{O}_{48}$ clusters with different degree of clusterization of $\mathrm{CdO}$ phase: $\mathrm{Cd}-\mathrm{O}$ atomic pairs are not merged (1), three $\mathrm{Cd}-\mathrm{O}$ atomic pairs are combined in clusters (2), four $\mathrm{Cd}-\mathrm{O}$ atomic pairs are grouped together (3); gray ball $-\mathrm{Cd}$, black ball - Zn; white ball - O.

has four regions, where $\mathrm{Cd}-\mathrm{O}$ pairs are not adjacent to each other. In the second case, three $\mathrm{Cd}-\mathrm{O}$ pairs are merged in cluster. In the last case, all four $\mathrm{Cd}-\mathrm{O}$ pairs are grouped together.

Optimized geometry, the total energy and band-gap energy of the clusters were determined using the hybrid B3LYP functional with basis set $3-21 \mathrm{G}(\mathrm{d})$. The cohesive energy was calculated as the difference between the total energy of the cluster and the total energy of its constituent non-interacting atoms without regard for the energy of zero vibrations.

GAMESS'09 [9], ChemCraft and Molekel 5.4 [10] programs were used for computations.

\section{Results and discussion}

As a result of computation procedure, the potential energy surface scan was performed and optimized geometry and electronic structure of the clusters were deter- mined. The minima of the potential energy surface suggest that optimized geometry is stable and the isolated Cd-containing fullerene-like $\mathrm{ZnO}$ cluster is formed. Energetic parameters of the (cohesive energy, band gap energy) $\mathrm{Zn}_{44} \mathrm{Cd}_{4} \mathrm{O}_{48}$ clusters are presented in Table I and Fig. 3.

TABLE I

Energetic parameters in $[\mathrm{eV}]$ of $\mathrm{Zn}_{44} \mathrm{Cd}_{4} \mathrm{O}_{48}$ clusters for different distributions of $\mathrm{CdO}$ atomic pairs: $E_{\text {tot. }}$ is the total energy, $E_{\mathrm{c}}$ is the cohesive energy of cluster, $E_{\mathrm{g}} / \mathrm{CdO}$ is the cohesive energy increase per one $\mathrm{Cd}-\mathrm{O}$ pair, $E_{\mathrm{g}}$ is the band gap energy.

\begin{tabular}{c|c|c|c}
\hline \hline$-E_{\text {tot. }}$ & $E_{\mathrm{c}}$ & $E_{\mathrm{e}} / \mathrm{CdO}$ & $E_{\mathrm{g}}$ \\
\hline \multicolumn{4}{c}{$\mathrm{CdO}+\mathrm{CdO}+\mathrm{CdO}+\mathrm{CdO}$} \\
\hline 2810273.558 & 613.382 & - & 2.819 \\
\hline \multicolumn{4}{c}{$(\mathrm{CdO}) \bullet 3+\mathrm{CdO}$} \\
\hline 810273.633 & 613.456 & 0.0371 & 2.688 \\
\hline \multicolumn{4}{c}{$(\mathrm{CdO}) \bullet 4$} \\
\hline 2810273.707 & 613.530 & 0.074 & 2.582
\end{tabular}



Fig. 3. Dependence of the cohesive energy and bandgap energy of $\mathrm{Zn}_{44} \mathrm{Cd}_{4} \mathrm{O}_{48}$ cluster on the number of combined $\mathrm{Cd}-\mathrm{O}$ atomic pairs.

Non-monotonic increase of the cohesive energy of the $\mathrm{Zn}_{44} \mathrm{Cd}_{4} \mathrm{O}_{48}$ cluster with increase in a degree of the clusterization of $\mathrm{CdO}$ phase is observed. When three $\mathrm{Cd}-\mathrm{O}$ pairs are grouped together the cohesive energy of the $\mathrm{Zn}_{44} \mathrm{Cd}_{4} \mathrm{O}_{48}$ cluster increases by $0.07414 \mathrm{eV}$. That is, the clusterization energy is equal to $0.037 \mathrm{eV}$ per one $\mathrm{Cd}-$ $\mathrm{O}$ pair. Adding to the previous $\mathrm{CdO}$ cluster the fourth $\mathrm{Cd}-\mathrm{O}$ pair leads to an enhancement of the cohesive energy of $\mathrm{Zn}_{44} \mathrm{Cd}_{4} \mathrm{O}_{48}$ cluster on $0.074 \mathrm{eV}$ (it is equal to clusterization energy of fourth $\mathrm{Cd}-\mathrm{O}$ pair). A reduction in band-gap energy from $2.82 \mathrm{eV}$ (Fig. 2(1)) to $2.69 \mathrm{eV}$ (Fig. 2(2)) and to $2.58 \mathrm{eV}$ (Fig. 2(3)) with increase in the degree of clusterization were revealed.

The revealed phenomenon of the $\mathrm{ZnCdO}$ alloys transition to more stable at nonhomogeneous distribution of $\mathrm{Cd}$ in $\mathrm{ZnO}$ is the analogue of spinodal decomposition. In Ref. [11] it was demonstrated that in $\mathrm{ZnCdO}$ alloys the isovalent $\mathrm{Cd}$ component nonhomogeneous distribu- 
tion is energetically beneficial. As a result the attempts of formation of $\mathrm{ZnO}-\mathrm{CdO}$ solid solution meet with great difficulties. In particular, the low solubility of $\mathrm{Cd}$ in $\mathrm{ZnO}$ matrix is frequently observed experimentally. Such phenomena significantly influence on the optical properties (the Raman scattering, photoluminescence etc.) of the ZnCdO ternary alloys.

Thus cluster approach for evaluation the energetic characteristics of $\mathrm{ZnCdO}$ alloys is useful for understanding spinodal decomposition phenomena on nanoscale level.

\section{Conclusions}

The model of fullerene-like $\mathrm{Zn}_{44} \mathrm{Cd}_{4} \mathrm{O}_{48}$ cluster with $s p^{2}$ bonds was implemented for study of the effect of $\mathrm{CdO}$ phase clusterization in $\mathrm{ZnCd}$ alloy on the stability, electronic structure and band gap energy of $\mathrm{ZnCdO}$ ternary alloys.

A possibility of formation of fullerene-like $\mathrm{Cd}$ containing $\mathrm{ZnO}$ clusters was shown.

It was revealed that the increase in the contribution of $\mathrm{CdO}$ phase to $\mathrm{Zn}_{44} \mathrm{Cd}_{4} \mathrm{O}_{48}$ cluster leads to nonlinear rapid increase in cohesive energy and cluster stability followed by band-gap energy shrinkage.

The present study and its further development may be used for the prediction and analysis of spinodal decomposition in $\mathrm{ZnCdO}$ ternary alloys and controllable synthesis of promising new $\mathrm{ZnO}$-based materials with variable band gap energy.

\section{Acknowledgments}

Computations were performed on the SKIT cluster of the Glushkov Institute of Cybernetics of NAS of Ukraine.

\section{References}

[1] G.V. Lashkarev, V.A. Karpyna, V.I. Lazorenko, A.I. Ievtushenko, I.I. Shtepliuk, V.D. Khranovskyy, Low Temp. Phys. 37, 226 (2011).

[2] A. Zaoui, M. Zaoui, S. Kacimi, A. Boukortt, B. Bouhafs, Mater. Chem. Phys. 120, 98 (2010).

[3] I. Shtepliuk, G. Lashkarev, O. Khyzhun, B. Kowalski, A. Reszka, V. Khomyak, V. Lazorenko, I. Timofeeva, Acta Phys. Pol. A 120, 914 (2011).

[4] L.I. Ovsiannikova, Acta Phys. Pol. A 122, 1062 (2012).

[5] L.I. Ovsiannikova, Acta Phys. Pol. A 124, 862 (2013).

[6] L.I. Ovsiannikova, Acta Phys. Pol. A 126, 1090 (2014).

[7] I.I. Shtepliuk, V. Khranovskyy , G. Lashkarev, V. Khomyak, V. Lazorenko, A. Ievtushenko, M. Syvajarvi, V. Jokubavicius, R. Yakimova, Solid-State Electron. 81, 72 (2013).

[8] Zhigang Zhu, A. Chutia, R. Sahnoun, M. Koyama H. Tsuboi, N. Hatakeyama, A. Endou, H. Takaba, M. Kubo, C.A. Del Carpio, Jpn. J. Appl. Phys. 47, 2999 (2008).

[9] M.W. Schmidt, K.K. Baldridge, J.A. Boatz, J.A. Boatz, S.T. Elbert, M.S. Gordon, J.H. Jensen, S. Koseki, N. Matsunaga, K.A. Nguyen, S.J. Su, T.L. Windus, M. Dupuis, J.A. Montgomery, J. Comput. Chem. 14, 1347 (1993).

[10] S. Portmann, H.-P. Lüthi, Chimia 54, 766 (2000).

[11] G.V. Lashkarev, I.I. Shtepliuk, A.I. Ievtushenko, O.Y. Khyzhun, V.V. Kartuzov, L.I. Ovsiannikova, V.A. Karpyna, D.V. Myroniuk, V.V. Khomyak, V.N. Tkach, I.I. Timofeeva, V.I. Popovich, N.V. Dranchuk, V.D. Khranovskyy, P.V. Demydiuk, Low Temp. Phys. 41, 129 (2015). 